\title{
Induction of partial immunity in both males and females is sufficient to protect females against sexual transmission of Chlamydia
}

\author{
CP O’Meara ${ }^{1,2}$, CW Armitage ${ }^{1}$, A Kollipara ${ }^{1}$, DW Andrew ${ }^{1,3}$, L Trim ${ }^{1}$, MB Plenderleith ${ }^{4}$ and \\ KW Beagley ${ }^{1}$
}

\begin{abstract}
Sexually transmitted Chlamydia trachomatis causes infertility, and because almost $90 \%$ of infections are asymptomatic, a vaccine is required for its eradication. Mathematical modeling studies have indicated that a vaccine eliciting partial protection (non-sterilizing) may prevent Chlamydia infection transmission, if administered to both sexes before an infection. However, reducing chlamydial inoculum transmitted by males and increasing infection resistance in females through vaccination to elicit sterilizing immunity has yet to be investigated experimentally. Here we show that a partially protective vaccine (chlamydial major outer membrane protein (MOMP) and ISCOMATRIX (IMX) provided sterilizing immunity against sexual transmission between immunized mice. Immunizing male or female mice before an infection reduced chlamydial burden and disease development, but did not prevent infection. However, infection and inflammatory disease responsible for infertility were absent in $100 \%$ of immunized female mice challenged intravaginally with ejaculate collected from infected immunized males. In contrast to the sterilizing immunity generated following recovery from a previous chlamydial infection, protective immunity conferred by MOMP/IMX occurred independent of resident memory Tcells. Our results demonstrate that vaccination of males or females can further protect the opposing sex, whereas vaccination of both sexes can synergize to elicit sterilizing immunity against Chlamydia sexual transmission.
\end{abstract}

\section{INTRODUCTION}

In Australia, Chlamydia trachomatis accounts for $81 \%$ of all notifiable sexually transmitted infections and cases have increased from 14,045 in 1999 to 74,305 in 2010. ${ }^{1}$ Women are two to three times more likely than men to contract an infection $^{2}$ and also have a higher incidence of asymptomatic infection, with 70-90\% compared with $40-60 \%$ in men. ${ }^{3}$ As the financial burden of Chlamydia infection is determined by the ease and cost of diagnosis, treatment, and management of associated diseases (e.g., infertility), women account for $80 \%$ of the total economic cost of Chlamydia infections. ${ }^{4}$ Consequently, developing a vaccine that protects females from infection and disease has been the primary focus, despite studies showing the benefits of targeting both sexes. ${ }^{5}$
We are reliant on animals to model infection transmission, and chlamydial research is most commonly conducted using the murine model, in which female mice require progesterone pretreatment to enhance their susceptibility to infection. ${ }^{6}$ Unfortunately, female mice become less receptive to mating during progesterone-induced diestrus, ${ }^{7}$ which prevents the study of sexual transmission between infected males and infection-susceptible female mice. Researchers instead used direct intravaginal inoculation of progesterone-primed female mice with Chlamydia to model sexual transmission. However, the infective dose can be highly variable between research groups, which can influence the kinetics of infection, immunity, and disease development. ${ }^{8,9}$ The inoculums of Chlamydia often used to infect mice are also considerably higher than the

${ }^{1}$ Department of Infectious Diseases, Institute of Health and Biomedical Innovation (IHBI), Queensland University of Technology (QUT), Brisbane, Queensland, Australia. ${ }^{2}$ Department of Developmental Immunology, Max Planck Institute of Immunobiology and Epigenetics, Freiburg, Baden-Wüttemburg, Germany. ${ }^{3}$ Department of Infectious Diseases, Centre for Biomedical Research, Burnet Institute, Melbourne, Victoria, Australia and ${ }^{4}$ Department of Biomedical Sciences, Neuroscience Laboratory—School of Biomedical Science, Queensland University of Technology (QUT), Brisbane, Queensland, Australia. Correspondence: KW Beagley (k2.beagley@qut.edu.au) 
amount identified in guinea pigs and humans to be passed naturally through sexual transmission. ${ }^{10-12}$ Direct intravaginal inoculation of female mice with Chlamydia in sucrose buffer also cannot replicate the effects male ejaculate has on female genital tract immunity. ${ }^{13}$ Therefore, there is a need to improve the current model of Chlamydia sexual transmission in mice to test intervention strategies like vaccines.

The chlamydial major outer membrane protein (MOMP) is the most commonly used antigen in chlamydial vaccine research. ${ }^{14}$ However, the superior quality of MOMP-specific immunity that develops following a natural infection with Chlamydia, as opposed to simple immunization with MOMP, suggests that current adjuvant technology is failing to fully exploit the protective capabilities of MOMP. Similar in structure to ISCOMs, ${ }^{15}$ ISCOMATRIX (IMX) is simply mixed with the antigen but does not need to encapsulate it to have an adjuvant effect, as the addition of phosphatidyl (choline or ethanol amine) into IMX during manufacturing provides exposed functional groups that allows for antigen conjugation through non-covalent interactions. IMX is safe and well tolerated in humans and shown to elicit long-lived T- and B-cell responses in clinical trials. ${ }^{15}$ As protection against a chlamydial genital tract infection is dependent on effective antigen presentation by dendritic cells and the induction of both $\mathrm{T}$ and $\mathrm{B}$ cells, ${ }^{16}$ the combination of MOMP and IMX together with intranasal administration to elicit a mucosal response could formulate an effective vaccine against a genital tract infection.

By challenging infection-susceptible (progesterone primed) female mice with ejaculates collected from infected males we could simulate Chlamydia sexual transmission in mice. Immunization with MOMP/IMX elicited partial protection against infection in both males and females; however, infection and disease were completely absent from immunized female mice challenged with infectious prostatic fluid collected from immunized males, indicating a synergism between the partial immunity in both sexes.

\section{RESULTS}

MOMP-specific T- and B-cell responses generated following immunization

A MOMP-specific cell-mediated and humoral immune response contributes significantly toward protection against a Chlamydia genital tract infection. ${ }^{17}$ We therefore isolated splenocytes from immunized mice and quantified the expansion and cytokine production of their T-helper cells (Th; $\mathrm{CD} 3+\mathrm{CD} 4+)$ and cytotoxic $\mathrm{T}$ cells $(\mathrm{Tc} ; \mathrm{CD} 3+\mathrm{CD} 8+)$ (Supplementary Figure 1 online) cells following in vitro restimulation with MOMP. Th, but not Tc cells isolated from MOMP/IMX immunized animals showed a significantly higher level of proliferation following restimulation with MOMP $(P<0.001)$ when compared with the unimmunized control (Figure 1a). MOMP-specific Th cells isolated from MOMP/ IMX immunized mice also showed significant staining for interferon- $\gamma \quad($ IFN $-\gamma) \quad(P<0.001)$, tumor-necrosis factor- $\alpha$ (TNF- $\alpha ; P<0.001$ ), interleukin-17 (IL-17); $P<0.001$ ) when compared with unimmunized controls (Figure 1b). Similarly, Tc cells displayed significant staining for IFN- $\gamma(P<0.05)$ and IL-17 $(P<0.001)$ when compared with unimmunized controls. Further analysis of the MOMP-specific Th cells isolated from the MOMP/IMX immunized animals indicated that $\sim 60 \%$ were multifunctional (IFN- $\gamma+$ TNF- $\alpha+$ IL- $17+$, TNF$\alpha+$ IL-17 $+\quad$ IFN- $\gamma+$ IL-17,$+ \quad P<0.001)$ compared with $<10 \%$ in the unimmunized control groups (Figure 1c). Tc cells in MOMP/IMX immunized mice were primarily of the single-positive phenotype (IFN- $\gamma+$, IL- $17+$, or TNF- $\alpha+)$ and not significantly different from the unimmunized control. Immune responses generated following immunization were identical in male and female mice (data not shown).

Immunization with MOMP/IMX generated MOMP-specific sera and vaginal $\operatorname{IgG}$ and $\operatorname{IgA}$ (Figure 1d) and these were significantly greater than those detected following an intravaginal infection (live infection control (LIC); $P<0.01)$. Sera from MOMP/IMX immunized mice significantly neutralized Chlamydia infectivity in vitro when compared with naïve sera $(P<0.05)$ (Figure 1e). Stimulation of RAW264.7 cells with Chlamydia opsonized with sera from MOMP/IMX immunized also promoted expression of CXCL1 (7-fold), CXCL2 (1.5-fold) and IL-1 $\beta$ (2-fold) messenger RNA (Figure 1f) after $24 \mathrm{~h}$ of stimulation.

\section{Determining the infectious dose of Chlamydia transmitted by male mice}

The bacterial burden in the prostatic fluid, prostate, and testes remained constant from weeks 1 to 10 post infection (p.i.) (Figure 2a and b). The bacterial burden in the penis peaked at week 10 p.i., although this had little effect on the total amount of viable Chlamydia collected in the prostatic fluid over the course of the infection. Males produced $4.7 \pm 1.7 \mu \mathrm{l}(\mathrm{BALB} / \mathrm{c})$ and $4.4 \pm 2.4 \mu \mathrm{l}$ (C57BL/6) of prostatic fluid (data not shown). The chlamydial load in the prostatic fluids contained $49 \pm 20$ inclusion-forming units (IFU) $(\mathrm{BALB} / \mathrm{c})$ and $64 \pm 35 \mathrm{IFU}$ (C57BL/6) of Chlamydia. Infected males were mated with receptive females (non-progesterone primed) at weeks 1 and 2 p.i. and the transmissible chlamydial load in their ejaculate was determined indirectly from the females (Figure $2 \mathrm{c}$ and $\mathbf{d}$ ). Samples collected from female mice that were mated with males at week 1 p.i. contained the most Chlamydia IFU. Vaginal lavages collected from mated BALB/c females contained $251 \pm 27$ IFU ( $\delta \mathrm{BALB} / \mathrm{c}$ ) and $258 \pm 34 \mathrm{IFU}(0 \mathrm{C} 57 \mathrm{BL} / 6$ ), while the vaginal plugs contained $225 \pm 153 \mathrm{IFU}$ ( $\$ \mathrm{BALB} / \mathrm{c}$ ) and $165 \pm 50 \mathrm{IFU}$ ( $\$ \mathrm{C} 57 \mathrm{BL} / 6$ ) of Chlamydia. For both direct and indirect sample collection methods, the transmissible dose was determined to be 18-503 IFU/ejaculate (Supplementary Figure 2).

\section{Protection against infection and disease in female mice following challenge with sexually transmissible doses of Chlamydia}

Vaginal shedding was significantly reduced in MOMP/IMX immunized animals challenged with $5 \times 10^{1}$ IFU on days 3 (15-fold; $P<0.001)$ and 6 p.i. (5-fold; $P<0.001)$ when compared with the unimmunized control group (Figure 3a). All unimmunized control animals challenged with $5 \times 10^{1}$ IFU of 
Chlamydia muridarum developed a cultivatable vaginal infection, whereas $20 \%$ of immunized animals remained culture negative from the point of challenge up until days 12-15 days post challenge. This suppressive effect on infection in the vagina was abrogated when immunized animals were challenged with doses of $1 \times 10^{2}$ IFU or greater. However, the
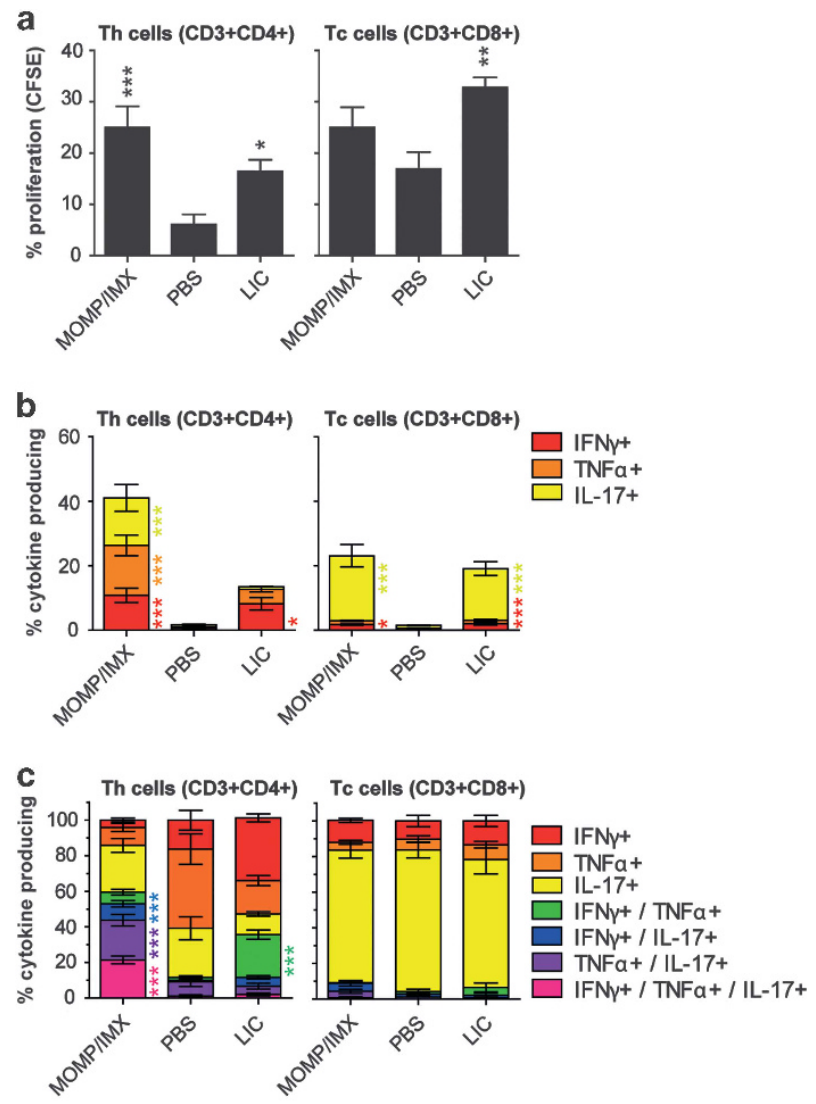

d
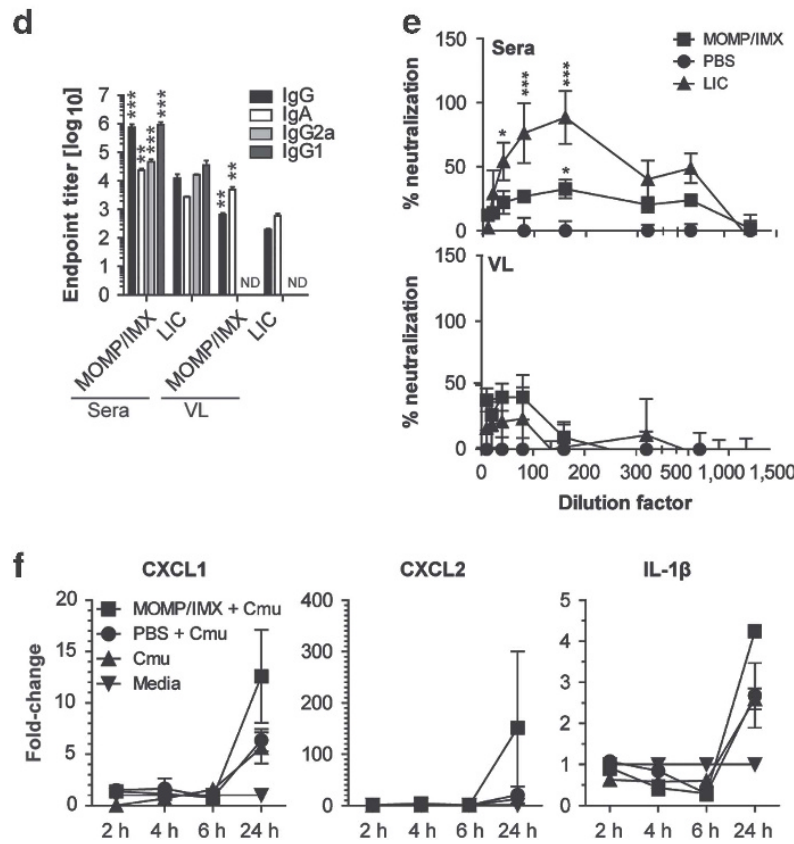

duration of infection and chlamydial shedding was still significantly reduced in the vagina of MOMP/IMX immunized animals when compared with the unimmunized control groups on day 6 p.i. (3-fold) when mice were challenged with $1 \times 10^{2}$ IFU $(P<0.001)$ (Figure $3 \mathbf{b}$ ), as well as on day 3 (4-fold) $(P<0.001)$ when mice were challenged with $5 \times 10^{2}$ IFU (Figure 3c). Immunized mice began clearing the infection in the lower genital tract from days 9-15 p.i., compared with days 21-35 p.i. for the unimmunized group. Immunization elicited a significant level of protection against the severity of oviduct pathology following challenge with $5 \times 10^{1}$ $\left(P<0.001\right.$; Figure 3a), $1 \times 10^{2}(P<0.001$; Figure $3 \mathbf{b})$, and $5 \times 10^{2}(P<0.01$; Figure $3 c)$, when compared with unimmunized controls. Mice recovered from a previous intravaginal chlamydial infection elicit sterilizing immunity against rechallenge. A prior infection (LIC) elicited sterilizing immunity against all challenge doses, but no protection against the development of oviduct pathology.

\section{Immune response in the genital tract of female mice following challenge with sexually transmissible doses of Chlamydia}

By isolating cells from the entire genital tract (sans ovaries) (Figure 4), we could identify differences in immune cell recruitment between immunized (MOMP/IMX), unimmunized (phosphate-buffered saline (PBS)) and immune mice (LIC) and link each cell infiltrate profile with its respective infection/disease protection profile. Leukocytes (CD45+; Figure 4a), neutrophils (CD45 + Gr-1+; Figure 4b), macrophages $(\mathrm{CD} 45+\mathrm{F} 4 / 80+$; Figure $4 \mathrm{c})$, B cells (CD45+

Figure 1 MOMP-specific T- and B-cell responses following immunization. Cells were isolated from spleens of immunized (MOMP/ IMX) or nonimmunized (PBS) mice (7 day post immunization) or infected mice (intravaginally challenged with $5 \times 10^{4} \mathrm{IFU}$ of $C$. muridarum, 21 day p.i.), stimulated with MOMP for 5 days and analyzed by flow cytometry for antigen-specific proliferation and cytokine production. Live cells (viability stain) were gated initially on single cells (FSC-A/FSC-H) and lymphocytes (FSC/SSC) before gating CD3 + cells on Th $(\mathrm{CD} 3+\mathrm{CD} 4+)$ and Tc cells $(\mathrm{CD} 3+\mathrm{CD} 8+)$. (a) Cells were labeled with CFSE and stimulated with MOMP to measure the percentages of MOMP-specific Th and Tc cell proliferation $(n=10)$. (b) MOMP-specific Th cells staining positive for IFN$\gamma$, TNF- $\alpha$, and IL-17 are represented as a percentage of total Th cells ( $n=10)$. (c) MOMP-specific Th cells staining positive for TNF- $\alpha$ were assessed for multifunctional phenotype (IFN- $\gamma$ and IL-17) are represented as a percentage of total cytokine producing Th cells $(n=10)$. (d) MOMPspecific $\lg$ G, IgA, IgG2a, and IgG1 end point titers were quantified in serum and vaginal lavage (VL) samples by ELISA. (e) In vitro neutralization of Chlamydia infectivity was determined for serum and vaginal lavage by culture $(n=10)$. (f) The ability of serum collected from MOMP/IMX immunized mice to opsonize Chlamydia and promote CXCL1, CXCL2, and IL-1 $\beta$ production by monocytes/macrophages (RAW264.7 cell line) was determined using reverse transcription PCR. Results are presented as the mean \pm s.e.m. ND refers to 'not done'. Significant differences were determined using a one-way ANOVA with Tukey's post test. Significance was set at $P<0.05$ for all tests. $P>0.05$ (not shown), 0.01-0.05 (*), $0.001-0.01\left(^{* *}\right)$, and $<0.001\left(^{* * *}\right)$. ANOVA, analysis of variance; CFSE, carboxyfluorescein succinimidyl ester; ELISA, enzyme-linked immunosorbent assay; IFN, interferon; IFU, inclusion-forming unit; IL, interleukin; IMX, ISCOMATRIX; MOMP, major outer membrane protein; Tc, T cells; Th, T-helper cells; TNF; tumor-necrosis factor; PBS, phosphate-buffered saline; p.i., post infection. 

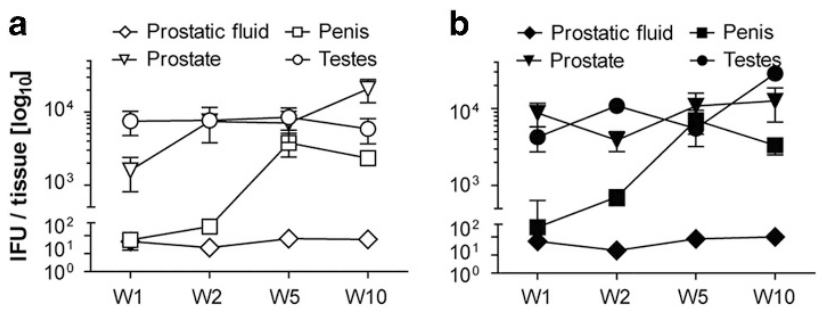

C
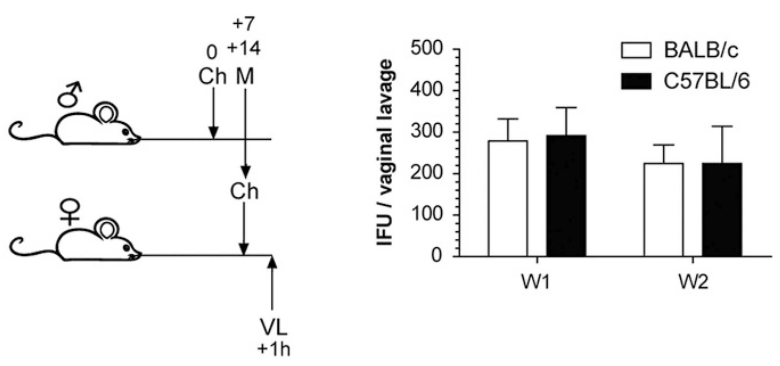

d

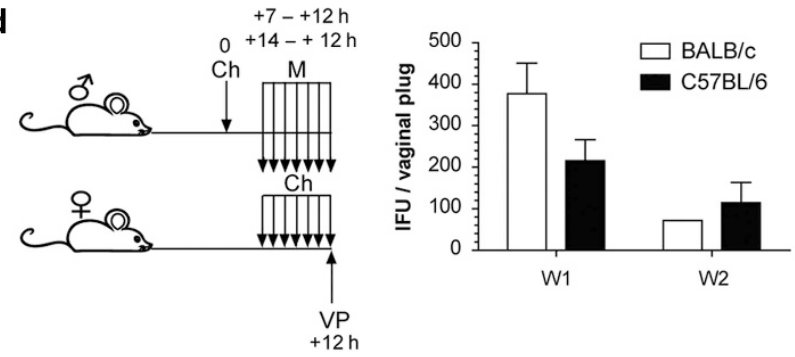

Figure 2 Quantification of the chlamydial dose sexually transmitted by male mice. (a) Male BALB/c and (b) C57BL/6 mice were challenged with $1 \times 10^{6} \mathrm{IFU}$ C. muridarum and the chlamydial burden was quantified from the prostatic fluid, penis, prostate, and testes collected on week 1,2,5, and 10 p.i. by culture $(n=5)$. (c) Male mice were challenged (Ch) with C. muridarum and mated (M) with non-progesterone primed females (receptive) and the chlamydial load transmitted was determined from vaginal lavages (VL; $n=11$ ) and (d) vaginal plugs (VP; $n=15)$ during weeks 1 and 2 of their infection. Results are presented, as the mean \pm s.e.m. Significant differences were determined using a one-way ANOVA with Tukey's post test. Significance was set at $P<0.05$ for all tests. $P>0.05$ (not shown), 0.01-0.05 $\left(^{*}\right), 0.001-0.01\left(^{* *}\right)$, and $<0.001$ $\left.{ }^{(* *}\right)$. ANOVA, analysis of variance; IFU, inclusion-forming unit; MOMP, major outer membrane protein; PBS, phosphate-buffered saline; p.i., post infection.

CD19+; Figure 4d) Th cells $(\mathrm{CD} 45+\mathrm{CD} 3+$;CD $4+$; Figure 4e) and Tc cells (CD45 + CD3 + CD8; Figure 4f) were analyzed (Supplementary Figure 3). Recruitment of B, Th, and Tc cells into the genital tracts occurred on day 8 following challenge in both immunized and unimmunized animals. Although number of $\mathrm{B}$, Th, and Tc cells recruited to the genital tract were consistently greater in immunized vs unimmunized mice, levels were not significantly different between groups. Tc cells were, however, present in significant numbers in the genital tracts of the LIC group before rechallenge (day 0; $(P<0.001)$ and on days 2 and 4 p.i. $(P<0.05)$ when compared with the unimmunized controls. Th cell numbers were also significantly increased in the female genital tracts of mice in the LIC when compared with unimmunized mice on days 2 and $4(P<0.05)$ following challenge, indicating a rapid recruitment of Th cells in the LIC group. Neutrophil and macrophage numbers were not significantly different between immunized and unimmunized mice. Uterine horn tissue sections were also stained for neutrophils (Gr-1 + ; Figure 4g), macrophages (F4/80 + ; Figure 4h), B cells (B220 + ; Figure 4i) and T cells (CD3 + ; Figure 4j), which matched those determined by flow cytometry. Interestingly, $8-15 \%$ of Tc cells isolated from the genital tract of mice from the LIC on day 2 p.i. were also $\mathrm{CD} 103+$, indicating they were tissue resident memory $\mathrm{T}$ cells $\left(\mathrm{T}_{\mathrm{RM}}\right)^{18}$ (Figure 5). However, $\mathrm{T}_{\mathrm{RM}}(\mathrm{CD} 3+\mathrm{CD} 8+\mathrm{CD} 103+$ ) diminished to background levels within 1 week of the secondary challenge.

Gene expression of immune cells sorted from the genital tract of female mice following challenge with a sexually transmissible dose of Chlamydia

As no significant differences in the anamnestic response were observed in the genital tract between immunized and unimmunized female mice, we assessed gene expression in wholeoviduct tissues (Figure 6a) and leukocytes recruited into the genital tract, sorted (Supplementary Figure 3) into macrophages (Figure 6b), neutrophils (Figure 6c), Tc cells (Figure 6d) and Th cells (Figure 6e) to identify functional differences. Th and Tc cells isolated on day 8 p.i. from MOMP/ IMX immunized mice expressed significantly more IFN- $\gamma$ (8- and 6-fold, respectively), TNF- $\alpha$ (2- and 6-fold, respectively), and IL-17A (10- and 12-fold, respectively) than unimmunized mice. Similarly, Th and Tc cells isolated on day 2 p.i. from LIC mice expressed significantly more IFN- $\gamma$ (6- and 2-fold, respectively), TNF- $\alpha$ (2- and 3-fold, respectively) and IL-17A (3- and 13-fold, respectively) than unimmunized mice on day 8 p.i. Neutrophils and macrophages isolated on day 8 p.i. from MOMP/IMX immunized mice expressed significantly more CXCL1 (2-fold) and IL-1 $\beta$ (2- and 4 -fold, respectively) than unimmunized mice. Similar increases in gene expression were also detected in the whole-oviduct tissues. This pattern of cytokine and chemokine expression in the oviduct of MOMP/IMX immunized mice on day 2 p.i. was similar to the gene expression RAW264.7 cell line stimulated with opsonized C. muridarum (Figure 1f).

\section{In vivo depletion and passive immunization}

To confirm the roles of $\mathrm{T}$ and $\mathrm{B}$ cells in protection in female mice, we depleted Th $(\mathrm{CD} 4+)$, Tc $(\mathrm{CD} 8 \beta+)$, and $\mathrm{B}$ cells $(\mathrm{CD} 20+)$ following immunization but before challenge. Th, Tc, and B cells (Supplementary Figure 4) were successfully depleted from the spleen and the genital tract following administration of $\alpha \mathrm{CD} 4, \alpha \mathrm{CD} 8$, and $\alpha \mathrm{CD} 20$, respectively. MOMP-specific Ig was not reduced in the serum or vaginal lavages of MOMP/IMX immunized mice following B-cell depletion (Supplementary Figure 4). Naïve mice were also passively immunized with sera collected from MOMP/IMX immunized mice. Serum antibody levels were found to be comparable between passively immunized and MOMP/IMX immunized mice (Supplementary Figure 4). Depletion of $\mathrm{CD} 4+$ and $\mathrm{CD} 8+$, but not CD20 + cells from MOMP/IMX immunized mice before challenge, inhibited protection against infection and oviduct pathology (Figure 7a). Depletion of 
a

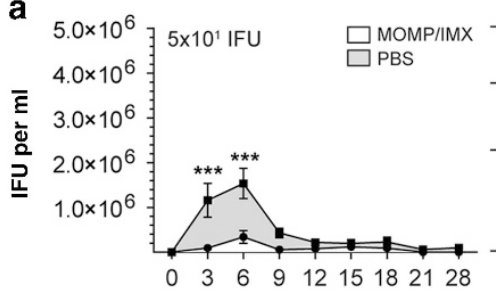

b
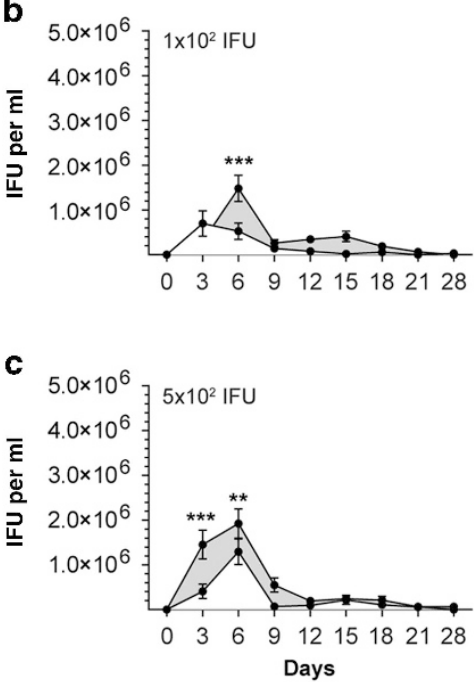

$\%$ of mice shedding Chlamydia from the vagina on days following an

\begin{tabular}{lllcccccccc} 
& \multicolumn{10}{c}{ intravaginal challenge } \\
\hline & & \multicolumn{10}{c}{$\begin{array}{c}\text { Dose } \\
\text { (IFU) }\end{array}$} & Group & & 3 & 6 & 9 & 12 & 15 & 18 & 21 & 28 \\
\hline \multirow{3}{*}{$5 \times 10^{1}$} & MOMP/IMX & $n=10$ & 80 & 70 & 70 & 70 & 80 & 90 & 40 & 20 \\
\cline { 2 - 10 } & PBS & $n=10$ & 100 & 100 & 100 & 100 & 100 & 100 & 80 & 70 \\
\cline { 2 - 10 } & LIC & $n=5$ & 0 & 0 & 0 & 0 & 0 & 0 & 0 & 0 \\
\hline
\end{tabular}

\begin{tabular}{|c|c|c|c|c|c|c|c|c|c|c|}
\hline \multicolumn{11}{|c|}{$\begin{array}{l}\% \text { of mice shedding Chlamydia from the vagina on days following an } \\
\text { intravaginal challenge }\end{array}$} \\
\hline \multirow{2}{*}{$\begin{array}{l}\text { Dose } \\
\text { (IFU) }\end{array}$} & \multirow{2}{*}{ Group } & & \multicolumn{8}{|c|}{ Days } \\
\hline & & & 3 & 6 & 9 & 12 & 15 & 18 & 21 & 28 \\
\hline \multirow{3}{*}{$1 \times 10^{2}$} & MOMP/IMX & $n=10$ & 100 & 100 & 100 & 80 & 40 & 70 & 40 & 50 \\
\hline & PBS & $n=10$ & 100 & 100 & 100 & 100 & 100 & 100 & 100 & 30 \\
\hline & LIC & $n=5$ & 0 & 0 & 0 & 0 & 0 & 0 & 0 & 0 \\
\hline
\end{tabular}

\begin{tabular}{llccccccccc}
\hline \multicolumn{1}{c}{ \% of mice shedding $\begin{array}{c}\text { Chlamydia from the vagina on days following an } \\
\text { intravaginal challenge }\end{array}$} \\
\cline { 3 - 11 } $\begin{array}{l}\text { Dose } \\
\text { (IFU) }\end{array}$ & Group & & 3 & 6 & 9 & 12 & 15 & 18 & 21 & 28 \\
\hline & MOMP/IMX & $n=10$ & 100 & 100 & 90 & 80 & 90 & 90 & 50 & 20 \\
\cline { 2 - 10 } $5 \times 10^{2}$ & PBS & $n=10$ & 100 & 100 & 100 & 100 & 100 & 100 & 100 & 60 \\
\cline { 2 - 10 } & LIC & $n=5$ & 0 & 0 & 0 & 0 & 0 & 0 & 0 & 0 \\
\hline
\end{tabular}

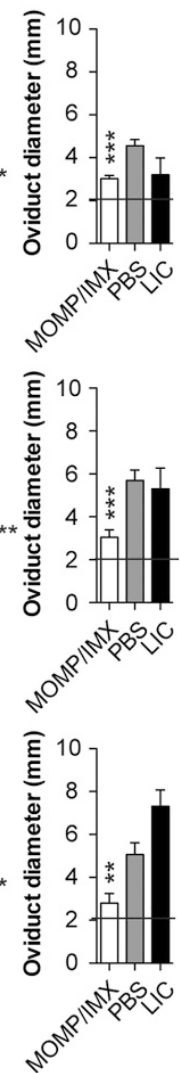

Figure 3 Protection against genital tract infection and oviduct pathology in female mice following immunization and challenge with sexually transmissible doses of $C$. muridarum. Female BALB/c mice were immunized (MOMP/IMX), nonimmunized (PBS) or infected ( $1^{\circ}$ infection, intravaginally challenged with $5 \times 10^{1}, 1 \times 10^{2}$, and $5 \times 10^{2}$ IFU of $C$. muridarum) then challenged with $(\mathbf{a}) 5 \times 10^{1}$, (b) $1 \times 10^{2},(\mathbf{c}) 5 \times 10^{2}$ IFU of $C$. muridarum. Vaginal swabs were collected over 28 days p.i. to quantify the amount of Chlamydia shed (IFU per ml) by culture. Significant levels of bacterial burden were determined using a two-way ANOVA with Tukey's post test. Results are presented as the mean \pm s.e.m. Percentages of mice shedding Chlamydia from the vagina on the days following challenge are also presented. Significant differences were determined using a Kaplan-Meier survival curve and the log rank post test. The severity of pathology was determined by measuring the diameter of the oviducts post mortem on day $35 \mathrm{p}$.i. The solid line across the graph represents the mean width of unaffected oviducts $(2 \mathrm{~mm})$. Significance of disease severity was determined using a one-way ANOVA with Tukey's post test. Significance was set at $P<0.05$ for all tests. $P>0.05$ (not shown), 0.01-0.05 $\left({ }^{*}\right), 0.001-0.01\left(^{* *}\right)$, and $<0.001\left(^{* * *}\right)$. ANOVA, analysis of variance; IFU, inclusion-forming unit; IMX, ISCOMATRIX; MOMP, major outer membrane protein; PBS, phosphate-buffered saline; p.i., post infection.

$\mathrm{CD} 4+$ but not $\mathrm{CD} 8+$ or $\mathrm{CD} 20+$ cells from unimmunized mice before challenge inhibited the natural resolution of the infection, but did not exacerbate oviduct pathology (Figure 7b). Depletion of $\mathrm{CD} 8+$ and $\mathrm{CD} 4+$ but not $\mathrm{CD} 20+$ cells before rechallenge mitigated sterilizing immunity in LIC mice, but did not exacerbate oviduct pathology (Figure 7c). Passive immunization of naïve mice with serum from MOMP/IMX mice reduced vaginal shedding between days 3 and 6 p.i. when compared with infusion of sera collected from unimmunized mice, but did not affect oviduct pathology (Figure 7d).

\section{Protection against Chlamydia infection transmission between male and female mice}

Immunization conferred partial protection against infection in female mice, although it is unclear if vaccinating males before their infection could prevent or reduce the risk of infection transmission to immunized female mice. Unimmunized female mice challenged with the prostatic fluid collected from unimmunized males (week 1 p.i.) developed a comparable vaginal infection and disease to females challenged with known doses of $5 \times 10^{1}, 1 \times 10^{2}$, and $5 \times 10^{2}$ IFU of $C$. muridarum (Figure 8a). Immunization of male mice before challenge significantly reduced the amount of Chlamydia detectable in the penis and testes, but not in prostatic fluid (Supplementary Figure 5). However, unimmunized female mice challenged with the infectious prostatic fluids from immunized males exhibited no reduction in infection or disease when compared with infection with unimmunized male ejaculates (Figure 8b). Half of immunized female mice showed sterilizing immunity against challenge with the infectious prostatic fluid from unimmunized males $(P<0.001)$, but these mice showed no protection from disease when compared with challenge of unimmunized females (Figure 8c). Interestingly, no immunized female mice challenged with the infectious ejaculate of immunized males acquired an infection or developed any oviduct pathology $(P<0.001$; Figure 8d), indicating complete protection against Chlamydia sexual transmission between immunized males and females. 


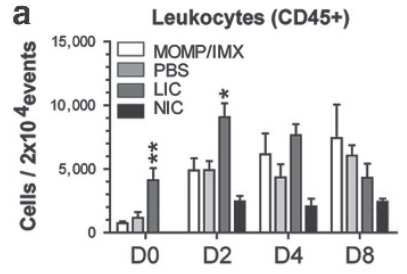

b
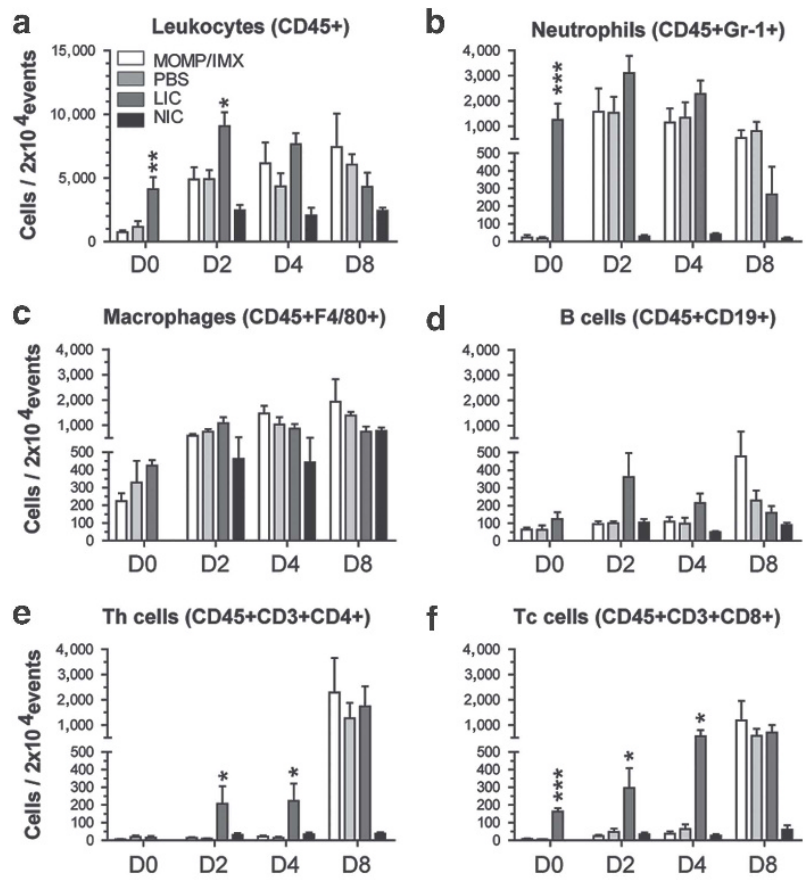

d

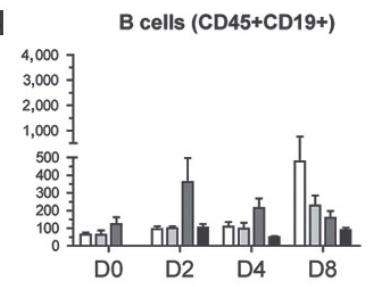

f

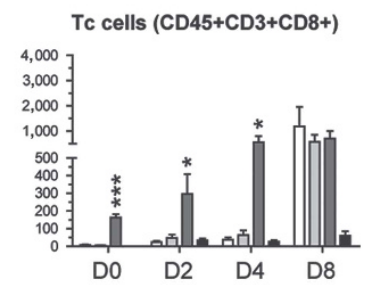

g

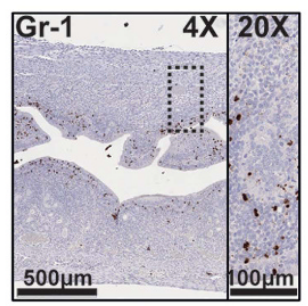

h

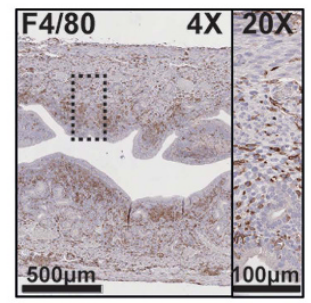

I
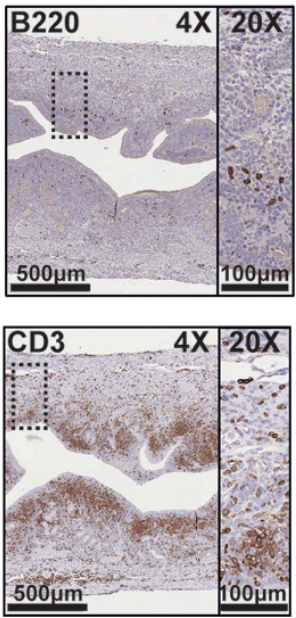
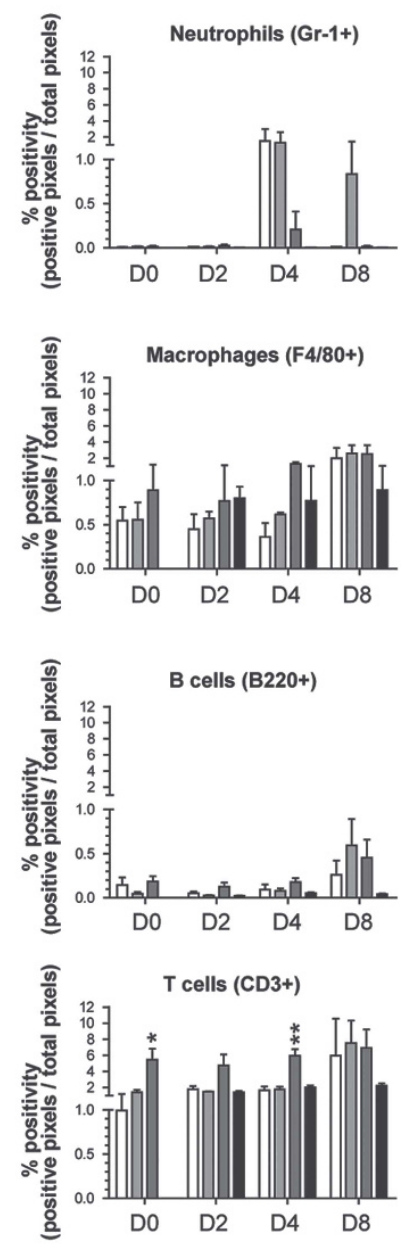

\section{DISCUSSION}

The ability of an animal model to replicate sexual transmission of infection is crucial for the development of a human vaccine against Chlamydia. To date, only large and/or expensive animal models (non-human primates, pigs, and guinea pigs) have been shown to transmit a chlamydial infection sexually. ${ }^{16}$ In this study, we determined the transmissible infectious dose in the ejaculate of male mice (18-503 IFU) to develop a mouse model of sexual transmission. This dose range determined for mice is comparable with guinea pigs that transmit $\sim 100 \mathrm{IFU}$ of Chlamydia caviae. ${ }^{11,12}$ Semen from C. trachomatis-infected human males has also been shown to contain between 675 and $1.6 \times 10^{4}$ copies per ml of chlamydial DNA. ${ }^{10}$ With an average ejaculate volume of $4.66 \mathrm{~mL},{ }^{10}$ a transmissible infectious dose for humans would range between 3,146 and $7.5 \times 10^{4}$ copies per ejaculate, which closely matches the amount contained in mouse prostatic fluid $\left(2,080-1.16 \times 10^{5}\right.$ copies per prostatic fluid). Therefore, we suggest that an inoculum of C. muridarum between 50 and 500 IFU should be used for all future vaccine studies as this dose is not only capable of establishing an infection in all test animals, but it also reflects a physiologically relevant inoculum that could be passed naturally during sexual transmission.

Surprisingly, $20 \%$ of immunized female mice initially resisted the establishment of a genital tract infection for 12-15 days post challenge with the sexually transmissible dose of 50 IFU. Despite the expansion of MOMP-specific and multifunctional Th and Tc cells following immunization, these could not be detected in the genital tract until day 8 p.i. Conversely, significant levels of MOMP-specific antibodies

Figure 4 Kinetics of leukocyte, neutrophil, macrophage, B, Th, and Tc cell recruitment following immunization and challenge with a sexually transmissible dose of $C$. muridarum. Female BALB/c mice were immunized (MOMP/IMX), nonimmunized (PBS), or infected ( $1^{\circ}$ infection, intravaginally challenged with $5 \times 10^{1}$ IFU of $C$. muridarum) then challenged with $5 \times 10^{1} \mathrm{IFU}$ of $C$. muridarum. Tissues were collected from immunized mice (MOMP/IMX and PBS) before challenge (day 0 ) and on days 2,4 , and 8 following challenge $(n=6)$. Tissues were also collected from uninfected animals (no infection control (NIC)) on days 2, 4, and 8 and mice recovering from an intravaginal infection (day $0=1^{\circ}$ infection, day 21 p.i.) and on days 2,4 , and 8 p.i. following rechallenge (live infection control $(\mathrm{LIC}))(n=6)$. Cells were isolated from the uterine horns and cervix/vagina by digestion for analysis by flow cytometry. Live cells (viability stain) were gated initially on single cells (FSC-A/FSC-H) and (a) leukocytes (CD45+) before gating on $($ b) neutrophils $(\mathrm{Gr}-1+)$, (c) macrophages $(\mathrm{F} 4 / 80+)$, (d) B cells $(\mathrm{CD} 19+)$, (e) Th cells $(\mathrm{CD} 3+\mathrm{CD} 4+)$ and (f) Tc cells $(\mathrm{CD} 3+\mathrm{CD} 8+)$. Results are presented as number of cells per $2 \times 10^{4}$ events. Uterine horns were also fixed for analysis by immunohistochemistry $(n=6)$. Serial tissue sections of the uterine horns were stained for the presence of $(\mathbf{g})$ neutrophils $(\mathrm{Gr}-1+),(\mathbf{h})$ macrophages $(\mathrm{F} 4 / 80+)$, (i) B cells $(\mathrm{B} 220+)$, (j) and T cells $(\mathrm{CD} 3+)$. Representative images (original magnifications $\times 4$ and $\times 20$ ) are shown for each stain. ImageScope software (Leica Biosystems, Nussloch, Germany) was used to quantify the percentage positivity (positive pixels/ total pixels) from a high-resolution image of each section. Results are presented as the mean \pm s.e.m. Significant differences were determined using a one-way ANOVA with Tukey's post test. Significance was set at $P<0.05$ for all tests. $P>0.05$ (not shown), 0.01-0.05 ( $\left.{ }^{*}\right), 0.001-0.01\left(^{* *}\right)$, and $\left.<0.001{ }^{\star * \star}\right)$. ANOVA, analysis of variance; IFU, inclusion-forming unit; IMX, ISCOMATRIX; MOMP, major outer membrane protein; PBS, phosphate-buffered saline; Tc, T cell; Th, T-helper cells; $T_{\mathrm{RM}}$, resident memory $\mathrm{T}$ cell. 

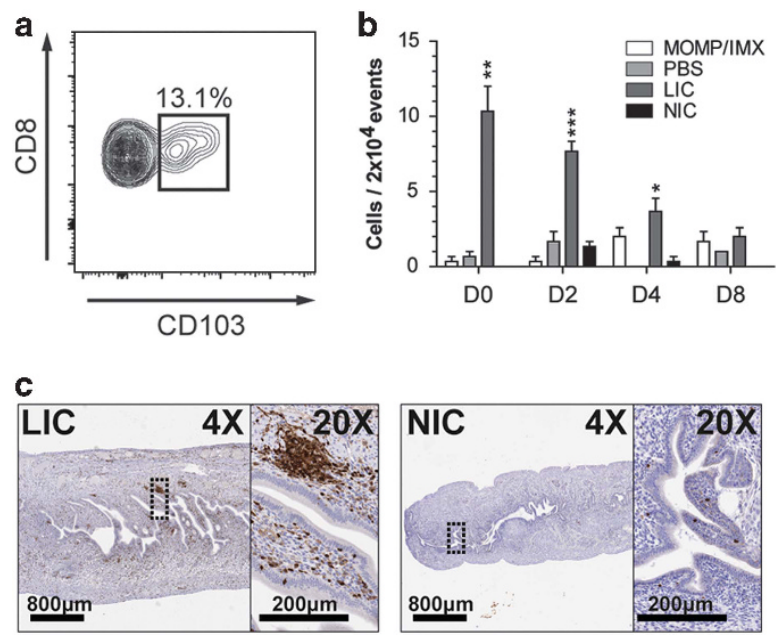

Figure 5 Kinetics of $\mathrm{T}_{\mathrm{RM}}$ cells $(\mathrm{CD} 3+\mathrm{CD} 8+\mathrm{CD} 103+)$ following immunization and challenge with a sexually transmissible dose of C. muridarum. Female BALB/c mice were immunized (MOMP/IMX), nonimmunized (PBS), or infected ( $1^{\circ}$ infection, intravaginally challenged with $5 \times 10^{1} \mathrm{IFU}$ of $C$. muridarum) then challenged with $5 \times 10^{1} \mathrm{IFU}$ of $C$. muridarum. Tissues were collected from immunized mice (MOMP/IMX and PBS) before challenge (day 0 ) and on days 2, 4 , and 8 following challenge $(n=3)$. Tissues were also collected from uninfected animals (no infection control (NIC)) and mice recovering from an intravaginal infection (day $0=1^{\circ}$ infection, day 21 p.i.) and on days 2, 4, and 8 p.i. following rechallenge (live infection control (LIC; $n=3$ ). Cells were isolated from the uterine horns and cervix/vagina by digestion for analysis by flow cytometry. (a) Resident memory Tc were identified by gating on lymphocytes (FSC/SSC), single cells (FSC-A/FSC-H), leukocytes $(\mathrm{CD} 45+)$, Tc cells $(\mathrm{CD} 3+\mathrm{CD} 8+)$, and finally CD103 + . (b) Cells per $2 \times 10^{4}$ events are presented for each group. Results are presented as the mean \pm s.e.m. (c) CD3 staining of tissue sections from uterine horns collected from LIC and NIC groups before challenge. Significant differences were determined using a one-way ANOVA with Tukey's post test. Significance was set at $P<0.05$ for all tests. $P>0.05$ (not shown), 0.01-0.05 $\left(^{*}\right), 0.001-0.01\left(^{* *}\right)$, and $\left.<0.001^{(* *}\right)$. ANOVA, analysis of variance; IFU, inclusion-forming unit; IMX, ISCOMATRIX; LIC, live infection control; MOMP, major outer membrane protein; PBS, phosphate-buffered saline; p.i., post infection; $T_{\mathrm{RM}}$, resident memory T cell.

were generated following immunization, which were also shown to neutralize Chlamydia infectivity in vitro and reduce vaginal shedding on days 3 and 6 p.i. following infusion into naïve animals. In support of findings by others, ${ }^{19}$ this indicates that induction of humoral immunity through immunization is crucial for neutralizing the initial challenge inoculum, an important effect that was masked when using higher, nonphysiological challenge doses of C. muridarum $\left(>5 \times 10^{3} \mathrm{IFU}\right)$ (data not shown).

Expression of chemokines (CXCL1, CXCL2, and CXCL5) and cytokines (IFN- $\gamma$, TNF- $\alpha$, and IL-1 $\beta$ ) were upregulated in the oviducts of immunized compared with unimmunized mice. Macrophages and neutrophils isolated from the genital tracts of immunized mice also showed a similar upregulated pattern of cytokine and chemokine expression as the oviducts, indicating an increased level of activation, antimicrobial and chemotactic activity. ${ }^{16}$ This occurred during the early stages of the infection (day 2 p.i.) where the presence of MOMP-specific antibodies in the genital tract of immunized animals was the only observed difference from unimmunized mice. Opsonization and complement are known to promote chemokines and cytokine production by $\mathrm{APCs}^{20}$ and we too found that Chlamydia incubated with sera containing MOMP-specific antibodies enhanced expression of cytokines and chemokines by monocyte/macrophages in vitro. This indicated that in addition to their neutralizing effects, antibodies generated following immunization might also contribute toward protection by enhancing innate and adaptive responses through the induction of cytokines and chemokines.

The recruitment of $\mathrm{T}$ cells into the genital tract on day 8 p.i. coincided with the resolution of the infection in immunized animals. However, unimmunized mice failed to resolve an infection from day 8 p.i. despite mounting a T-cell response comparable in both speed and magnitude to immunized animals. This indicated that functional differences existed between $\mathrm{T}$ cells recruited in immunized and unimmunized animals. Immunization induced expansion of MOMP-specific splenic Th and Tc cells, which produced IFN- $\gamma$, TNF- $\alpha$, and IL$17 \mathrm{~A}$ on in vitro restimulation. Th and Tc cell isolated from the genital tracts of immunized mice on day 8 p.i. were also found to express more IFN- $\gamma$, TNF- $\alpha$, and IL-17A than T cells isolated from unimmunized animals. These cytokines have been consistently shown to contribute to protection against infection and disease. ${ }^{21}$ Protection against vaginal shedding was alleviated following depletion of CD4 + and CD8 + cells, indicating an important role for Th and Tc cells in protection elicited by MOMP/IMX.

Animals recovered from a previous infection with Chlamydia (LIC group) demonstrated sterilizing immunity against rechallenge; therefore, it is important to compare the mechanisms of protection between MOMP/IMX immunized and LIC mice as this can highlight potential inadequacies in vaccine design. $\mathrm{T}$ cells were not detectable in the genital tract of MOMP/IMX immunized until day 8 p.i., whereas Tc cells were present in the genital tract of LIC mice before rechallenge and Th cells were rapidly recruited by day 2 p.i. Some Tc cells present in the genital tract of LIC mice before challenge were CD103 + and localized in the epidermis, which is consistent with the phenotype of $T_{R M}$ in female genital tract of mice during a Herpes simplex virus-2 infection. ${ }^{22}$ However, $T_{R M}$ were not detected in the genital tract of MOMP/IMX immunized mice even following challenge (days 2-8 p.i.). Tc cells isolated from the genital tracts of mice in the LIC group immediately before rechallenge (day 2 p.i.) expressed increased levels of cytokines, which were associated with the rapid recruitment of Th cells. This is also consistent with existing literature regarding the functionality of $\mathrm{T}_{\mathrm{RM}}$, that they provide a means of 'sense and alarm ${ }^{23}$ by secreting cytokines and chemokines, which recruit effector Th cells necessary to eradicate the infection. Th and Tc cells recruited in the genital tract of MOMP/IMX immunized mice exhibited a similar pattern of increased cytokine expression as $\mathrm{T}$ cells from LIC, but were recruited later at day 8 p.i. Reduction of Tc cells number, including the $T_{R M}$, in the genital tract of LIC mice before rechallenge abrogated sterilizing immunity, which indicated that Tc cells are capable of preventing infection from sexually transmissible doses of 


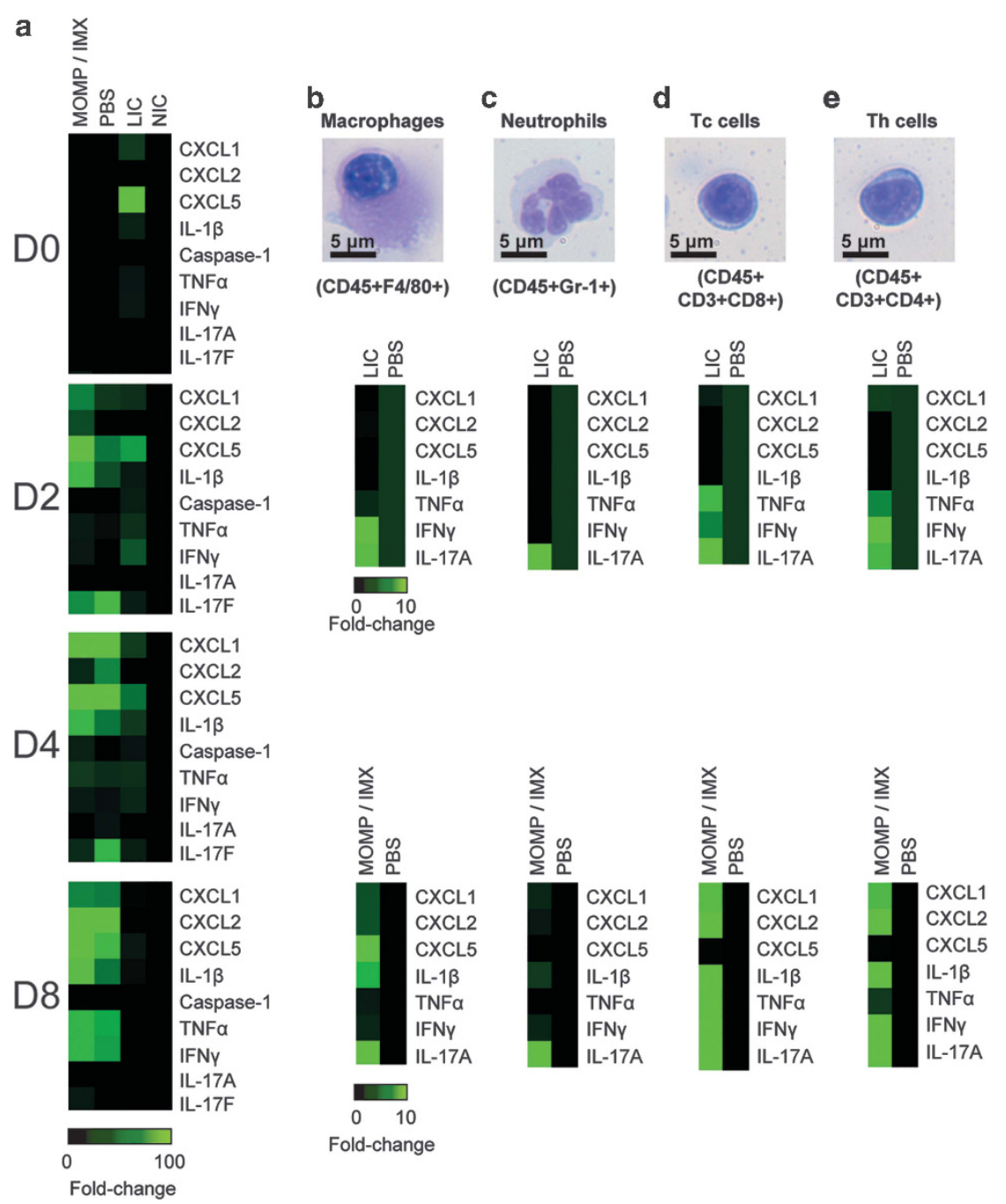

Figure 6 Gene expression in whole oviducts, macrophages, neutrophils, Tc, and Th cells isolated from the oviducts following immunization and challenge with a sexually transmissible dose of $C$. muridarum. Female BALB/c mice were immunized (MOMP/IMX), nonimmunized (PBS), or infected $\left(1^{\circ}\right.$ infection, intravaginally challenged with $5 \times 10^{1} \mathrm{IFU}$ of $C$. muridarum) then challenged with $5 \times 10^{1} \mathrm{IFU}$ of $C$. muridarum. Tissues were collected from immunized mice (MOMP/IMX and PBS) before challenge (day 0 ) and on days 2, 4, and 8 following challenge. Tissues were also collected from uninfected animals (NIC) and mice recovering from an intravaginal infection (day $0=1^{\circ}$ infection, day 21 p.i.) and on days 2,4 , and 8 p.i. following rechallenge (live infection control (LIC); $(n=3)$. (a) Gene expression was performed on pooled oviducts $(n=3)$ and fold change (scale 0 - 100 -fold) was calculated relative to the uninfected control (NIC). Live cells were isolated from the genital tract on days 2 and 8 p.i. and separated into (b) macrophages (CD45 + F4/80 +) (c) neutrophils (CD45 + Gr-1 +), (d) Tc (CD45 + CD3 + CD8 +), and (e) Th cells (CD45 + CD3 + CD4 +) using flow cytometry ( $n=10)$. Cytospin and Geimsa staining was performed on sorted cell fractions to compare surface marker phenotype with nuclear morphology (representative image shown). Gene expression was performed on pooled cells isolated from the oviducts, uterine horns and cervix vagina $(n=10)$, and fold changes (scale $0-10$-fold) were calculated relative to an unimmunized control. Significant differences were determined using a one-way ANOVA with Tukey's post test. Significance was set at $P<0.05$ for all tests. $P>0.05$ (not shown), 0.01-0.05 (*), 0.001-0.01 (**), and $<0.001\left(^{* * *}\right)$. ANOVA, analysis of variance; IFU, inclusionforming unit; IMX, ISCOMATRIX; MOMP, major outer membrane protein; Tc, T cells; Th, T-helper cells; PBS, phosphate-buffered saline; p.i., post infection.

Chlamydia. Th cells were also shown to contribute to sterilizing immunity in LIC mice, however; it is unclear if Th cells had a direct effect or if their depletion during the resolution of the primary infection inhibited the development of $\mathrm{T}_{\mathrm{RM}} \cdot{ }^{24}$ Further phenotypic characterization, functionality and longevity studies will also be required to definitively characterize $T_{R M}$, although this to our knowledge is the first indication that a small number of $\mathrm{T}_{\mathrm{RM}}$ may be generated following a chlamydial infection. Comparison between immunized and LIC mice indicate that strategies to accelerate $\mathrm{T}$-cell recruitment into the genital tract, like the 'prime-pull' approach, ${ }^{25}$ must be implemented if future vaccines are to achieve immunity equivalent to that which develops following a natural infection.

Mathematical modeling has been invaluable in determining the attributes a vaccine must possess in order to impact on infection transmission. ${ }^{5,26}$ Assertions that non-sterilizing vaccines, if targeted toward both sexes, could interrupt infection transmission had not yet been investigated experimentally. ${ }^{5}$ Challenging female mice with prostatic fluids collected from infected males to model sexual transmission (Figure 9a), we determined that the immunization status (immunized or unimmunized) of both sexes was critical for the 

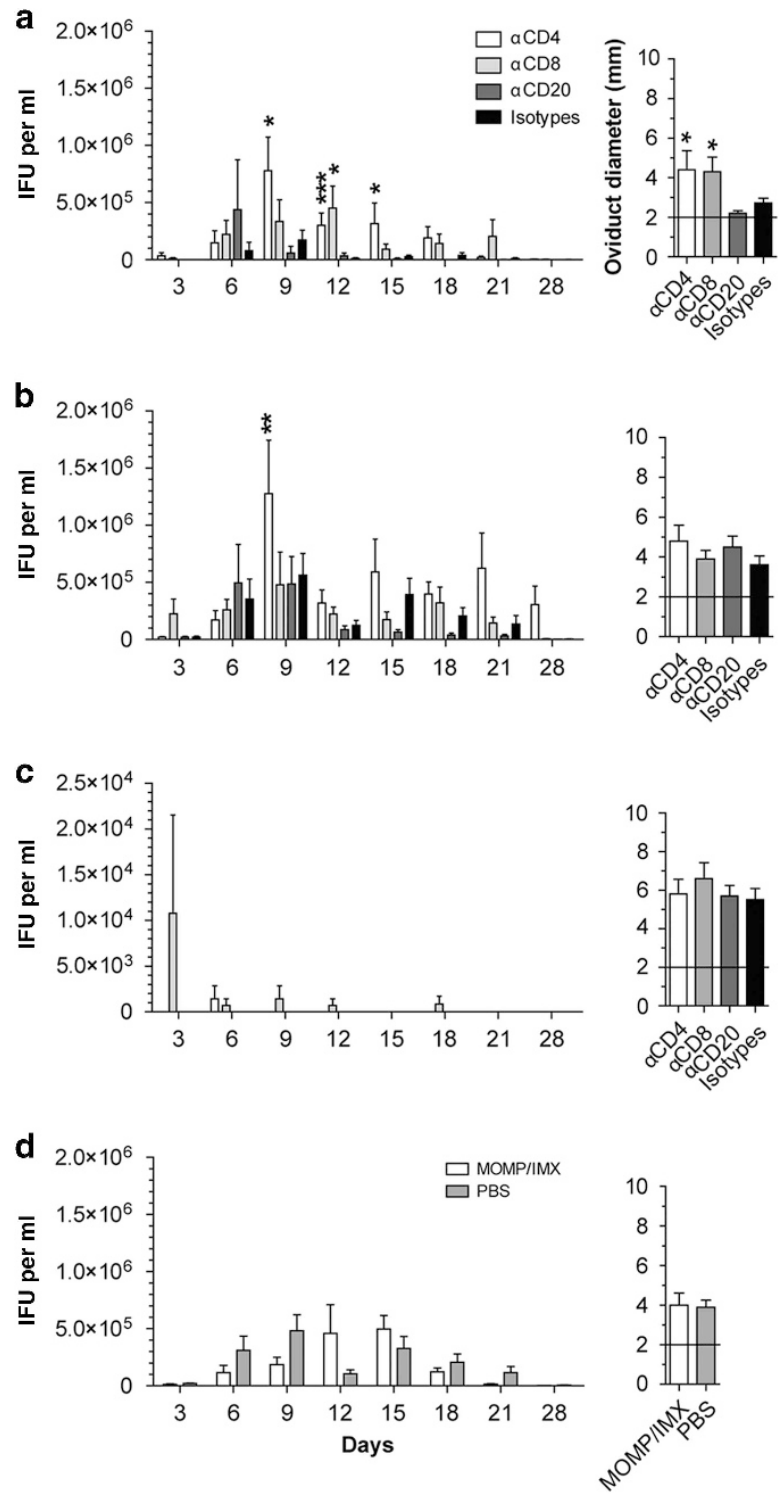

Figure 7 In vivo depletion (CD4 +, CD8 +, and CD20 + ) and passive immunization before challenge with a sexually transmissible dose of C. muridarum. Female BALB/c mice were immunized (MOMP/IMX), nonimmunized (PBS), or infected $\left(1^{\circ}\right.$ infection, intravaginally challenged with $5 \times 10^{4}$ IFU of $C$. muridarum) and depleted of CD4, CD8, and CD20 cells $(n=5)$. Unimmunized mice were also passively immunized with serum collected from MOMP/IMX immunized mice $(n=5)$. Depleted and passively immunized mice were then challenged with $5 \times 10^{1} \mathrm{IFU}$ of C. muridarum. Vaginal infection and oviduct pathology were quantified from (a) MOMP/IMX, (b) unimmunized, (c) LIC and (d) passively immunized naïve mice. Vaginal swabs were collected for 28 days p.i. to quantify the amount of Chlamydia shed (IFU per ml) by culture. The severity of pathology was determined on day 35 p.i. by measuring the diameter of the oviducts. The solid line across the graph represents the mean width of unaffected oviducts $(2 \mathrm{~mm})$. Results are presented as the mean \pm s.e.m.. Significant levels of bacterial burden and disease severity were determined using a one-way ANOVA with Tukey's post test. Significance was set at $P<0.05$ for all tests. $P>0.05$ (not shown), $0.01-0.05\left(^{\star}\right), 0.001-0.01\left(^{* *}\right)$, and $<0.001\left(^{* * *}\right)$. ANOVA, analysis of variance; IFU, inclusion-forming unit; IMX, ISCOMATRIX; LIC, live infection control; MOMP, major outer membrane protein; PBS, phosphate-buffered saline; p.i., post infection. induction of sterilizing immunity against infection and disease. Immunizing females was more effective against preventing infection transmission than immunizing males (Figure $9 \mathbf{b}$ and c), as reported elsewhere. ${ }^{5}$ This could be attributed to the inherent difficulties in resolving an infection in the immuneprivileged male genital tract and the vaccine eliciting a potent cell-mediated response as opposed to the more male protective humoral response. ${ }^{27}$ However, male vaccination status protected against the development of oviduct pathology in immunized females (Figure 9d). As this reduction in severity and incidence of disease was not detected in unimmunized females, it is likely to be independent of bacterial burden. Instead, additional adaptive immune components like antibodies, chemokines, or cytokines present in the ejaculate of immunized males may have provided cross talk with immunity in immunized females. ${ }^{13,28}$ This indicates that anti-chlamydial immunity against infection will be dependent on a vaccine for females, whereas a vaccine targeting males may be required for protection against diseases associated with infertility.

In this study, analysis of the local immune response in the genital tract following a Chlamydia infection provides the first evidence that $\mathrm{T}_{\mathrm{RM}}$ confer/are essential for sterilizing immunity against challenge and should be the target of future vaccines. Induction of $\mathrm{T}_{\mathrm{RM}}$ in females may be required to elicit complete protection against an infection transmitted from an unimmunized male. A partially protective vaccine targeting females would have a greater impact on Chlamydia infection and disease than a male vaccine; however, sterilizing immunity, i.e., prevention of sexual transmission, would require vaccination of both sexes. It has been consistently shown in the most at risk adolescent age group that sexual behavior and perception of risk to other sexually transmitted infections is unaltered by vaccination; ${ }^{29}$ therefore, the introduction of a non-sterilizing Chlamydia vaccine together with existing surveillance and antibiotic treatment programs could facilitate a decline in infection rates.

\section{METHODS}

Animals and Chlamydia. Mice (C57BL/6 and BALB/c) were sourced from the Animal Resource Centre (ARC, Canningvale, WA, Australia) at 6 weeks of age. Animals were given food and water ad libitum. C. muridarum (Weiss strain), was a generous gift from Catherine O'Connell and cultured from McCoy cells and purified as previously described. $^{30}$

Immunization. Recombinant C. muridarum MOMP-maltose binding protein was purified and intranasal immunizations were performed as previously described. ${ }^{31}$ The vaccine contained recombinant MOMP $(50 \mu \mathrm{g})$ and ISCOMATRIX $(10 \mu \mathrm{g})$ (Zoetis, Florham Park, NJ) mixed in a $10 \mu \mathrm{l}$ volume, $5 \mu \mathrm{l}$ applied to each nare. Animals were immunized once on four separate occasions (days $0,7,14$, and 28).

Antibodies and flow cytometry. Cells were washed with $2 \% \mathrm{v} / \mathrm{v}$ fetal calf serum/PBS before blocking with $\alpha \mathrm{CD} 16 / \mathrm{CD} 32-\mathrm{Fc} \gamma \mathrm{R}$ (Clone: 24G2) for $15 \mathrm{~min}$ at $4{ }^{\circ} \mathrm{C}$. Cells were labeled with Zombie Green Viability Dye (Cat No. 423112, Biolegend, San Diego, CA) before staining with $\alpha \mathrm{CD} 3$ (Clone: 145-2C11, Cat No 100330-Biolegend), aCD4 (Clone: RM4.5, Cat No. 562314-BD Bioscience, San Jose, CA), $\alpha \mathrm{CD} 8 \alpha$ (Clone: 53.6-7, Cat No. 25-0081-eBioscience, San Diego, CA), $\alpha$ CD19 (Clone: 1D3, Cat No. 551001-BD Bioscience, Franklin 
$\mathbf{a}$
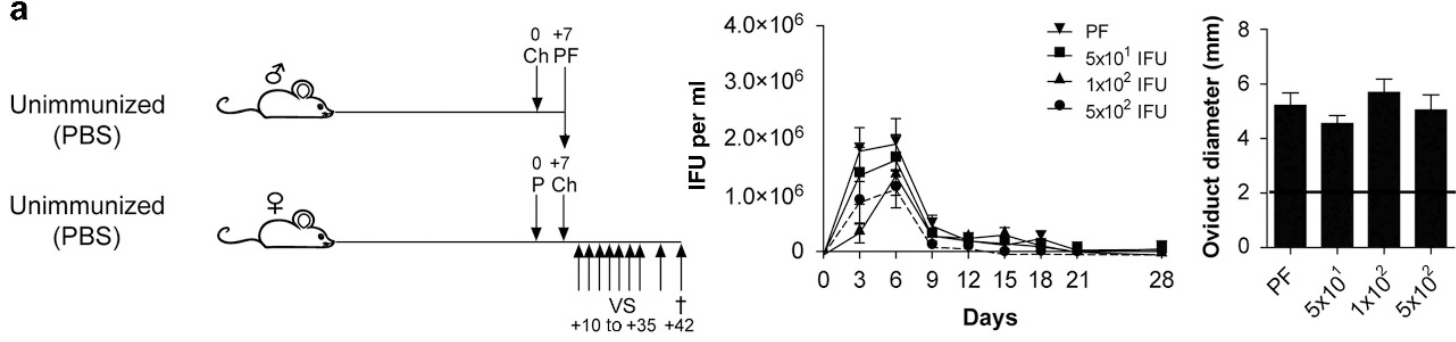

b
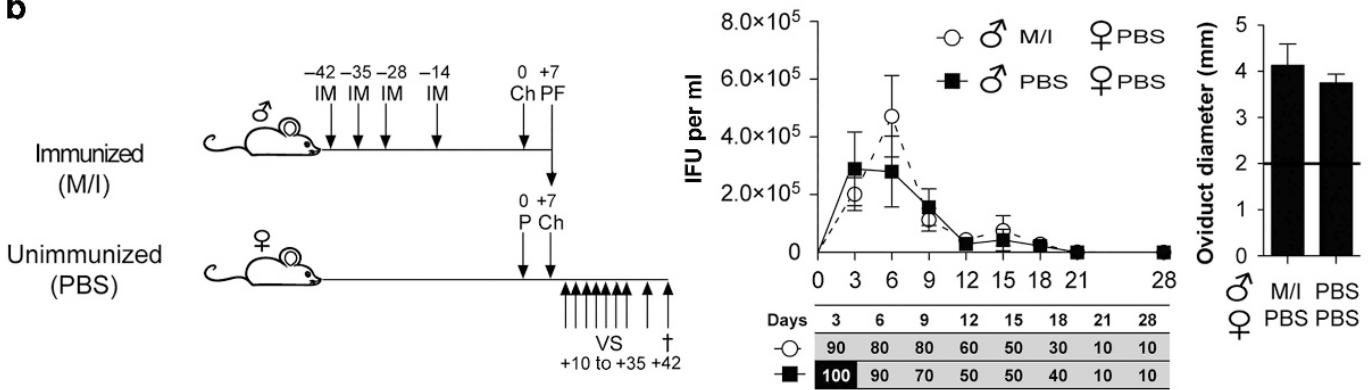

C
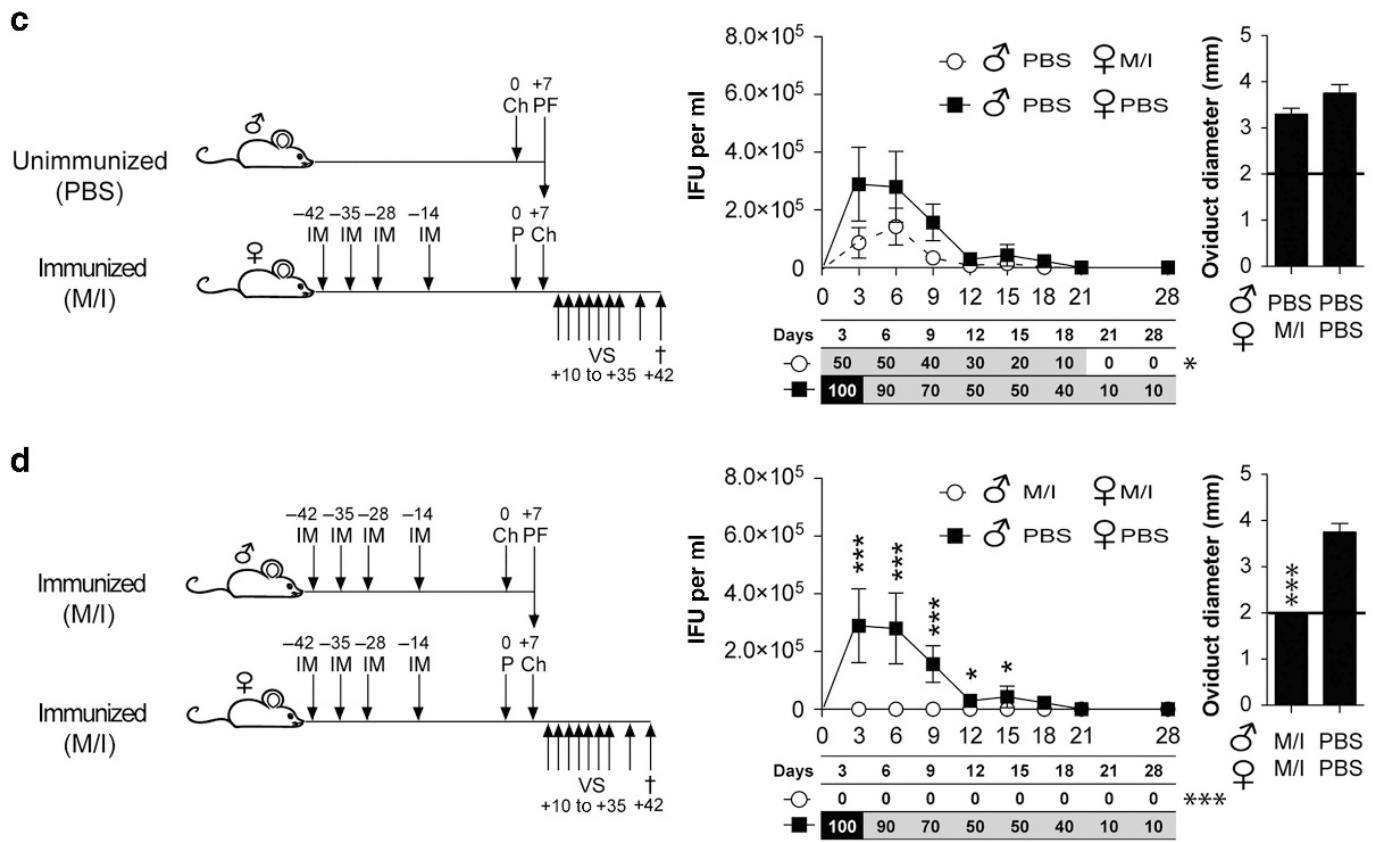

Figure 8 Transmission of Chlamydia between male and female mice with different vaccination statuses. (a) Male mice were challenged (Ch) with $1 \times 10^{6} \mathrm{IFU}$ C. muridarum and their prostatic fluids (PF) were collected 7 days p.i. $(n=10)$. Female mice were progesterone primed $(\mathrm{P}) 7$ days before being challenged intravaginally with prostatic fluid collected from the infected males $(n=5)$. Vaginal shedding and development of hydrosalpinx following challenge with PF was compared to challenge of female mice with $5 \times 10^{1}, 1 \times 10^{2}$, and $5 \times 10^{2}$ of $C$. muridarum. This model of sexual transmission was repeated using (b) males, (c) females and (d) males and females that had been immunized (IM) with MOMP/IMX (M/I) before challenge with PF $(n=10)$. Vaginal swabs (VS) were collected over 28 days p.i. to quantify the amount of Chlamydia shed (IFU per ml) by culture. Significant levels of bacterial burden were determined using a two-way ANOVA with Tukey's post test. Results are presented as the mean \pm s.e.m. Percentages of mice shedding Chlamydia from the vagina on the days following challenge are also presented. Significant differences were determined using a Kaplan-Meier survival curve and the log rank post test. Protection against the severity of oviduct pathology (hydrosalpinx) in female mice challenge with prostatic fluid was determined post mortem (killed, $\dagger$ ) on day 35 p.i. by measuring oviduct diameter. The solid line across the graph represents the mean width of unaffected oviducts ( 2 mm). Results are presented as the mean \pm s.e.m. Significant levels of bacterial burden and disease severity were determined using a one-way ANOVA with Tukey's post test. Significance was set at $P<0.05$ for all tests. $P>0.05$ (not shown), $0.01-0.05\left(^{*}\right), 0.001-0.01\left(^{* *}\right)$, and $<0.001\left(^{* * *}\right)$. ANOVA, analysis of variance; IFU, inclusion-forming unit; IMX, ISCOMATRIX; MOMP, major outer membrane protein; p.i., post infection.

Lakes, NJ), $\alpha$ CD45 (Clone: 30-F11, Cat No. 562129-BD Bioscience), aCD103 (Clone: 2E7, Cat No. 121408-Biolegend), $\alpha \mathrm{Gr}-1-\mathrm{Ly} 6 \mathrm{C} /$ Ly6G (Clone: RB6-8C5, Cat No. 108412-Biolegend), and $\alpha \mathrm{F} 4 / 80$ (Clone: BM8, Cat No. 123110-Biolegend) in a volume of $50 \mu \mathrm{l}$ for
15 min at $4{ }^{\circ} \mathrm{C}$. Cells were washed with $2 \%$ fetal calf serum/PBS before fixing using $4 \% \mathrm{w} / \mathrm{v}$ paraformaldehyde for $10 \mathrm{~min}$ at $4{ }^{\circ} \mathrm{C}$. Fixed cells were permeabilized for intracellular cytokine staining using Perm/Wash (Cat No. 554723-BD Bioscience) according to the 

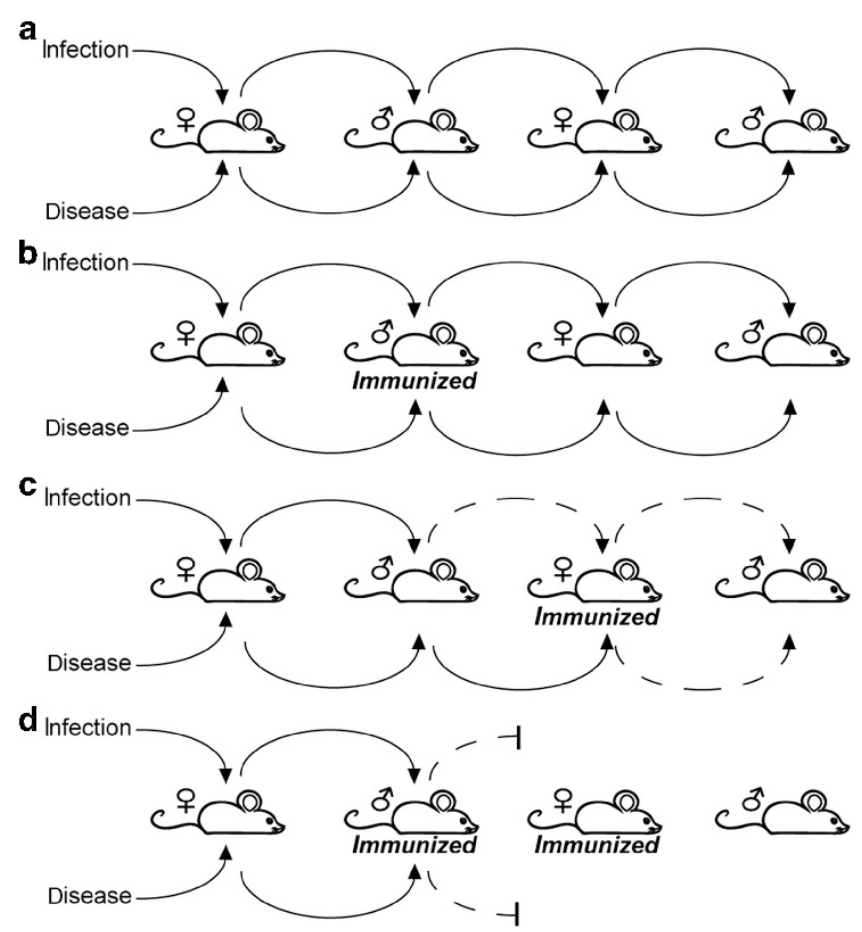

Figure 9 Prevention of Chlamydia sexual transmission by vaccination.(a) Chlamydia infection transmission occurs unimpeded though unimmunized mice. (b) Risk of infection transmission to unimmunized females is unaffected by the male vaccination status. (c) Vaccinating female mice reduces their risk of acquiring an infection from unimmunized males by $50 \%$, but not their risk of developing disease. As half of immunized females were protected from an infection, risk of infection transmission and disease developing in unimmunized males is also reduced. (d) No transmission of infection occurs between immunized males and females. Immunized females show no signs of disease. Further transmission to unimmunized males is also prevented.

manufacturer's instructions. Permeabilized cells were stained with $\alpha$ IFN- $\gamma$ (Clone: XMG1.2, Cat No. 554413-BD Bioscience), $\alpha$ TNF- $\alpha$ (Clone: MP6-XT22, Cat No. 554418-BD Bioscience), and $\alpha \mathrm{IL}-17$ (Clone: TC11-18H10, Cat No. 559502-BD Bioscience) diluted in Perm/Wash buffer for $40 \mathrm{~min}$ at $4{ }^{\circ} \mathrm{C}$. Stained cells were analyzed on the FACSAria III (BD Bioscience) using Flowjo version X software (Tree Star Inc, Ashland, OR).

In vivo depletion and passive immunization. Depletion of $\mathrm{CD} 4+$ (Clone: GK1.5, IgG2b, $1 \times 200 \mu \mathrm{g}$ ), CD $8 \beta+$ (Clone: $53-5.8,{ }^{32}$ IgG1, $1 \times 250 \mu \mathrm{g}$ intraperitoneal, $2 \times 50 \mu \mathrm{g}$ intravaginally; BioXcell, West Lebanon, $\mathrm{NH}$ ) and CD20 + cells (Clone: 5D2, IgG2a, $1 \times 250 \mu \mathrm{g}$; Genentech Inc, San Francisco, CA) was performed following intraperitoneal injection of each monoclonal antibody on day 13 before intravaginal challenge. Identical doses of $\alpha \mathrm{TNP}$ (Clone: 2A3, IgG2a), $\alpha$ HRP (Clone: HRPN, IgG1), or $\alpha \mathrm{KLH}$ (Clone: LTF-2, IgG2b; BioXcell) were used as isotype controls. Passive immunization of naïve mice was performed one day before intravaginal challenge by intraperitoneal infusion of $500 \mu \mathrm{l}$ of serum collected from MOMP/ IMX or PBS immunized mice.

Sample collection and tissue processing. Vaginal lavages and serum were collected as previously described. ${ }^{21}$ Spleens processed as described previously ${ }^{21}$ and cultured in complete Dulbecco's minimal essential medium $(5 \% \mathrm{v} / \mathrm{v}$ fetal calf serum, $4 \mathrm{mM} \mathrm{L}$-glutamine, $50 \mu \mathrm{g} \mathrm{ml}^{-1}$ gentamicin, and $100 \mu \mathrm{g} \mathrm{ml}^{-1}$ streptomycin sulfate;
Invitrogen, Carlsbad, CA) containing $50 \mu \mathrm{M} \quad \beta$-mercaptoethanol. Genital tract tissues were digested in complete Dulbecco's minimal essential medium containing $500 \mathrm{U} \mathrm{ml}^{-1}$ of collagenase I and $120 \mu \mathrm{g} /$ $\mathrm{ml}^{-1}$ DNase I (Invitrogen) for $1 \mathrm{~h}$ shaking at $37^{\circ} \mathrm{C}$.

MOMP-specific T-cell proliferation and cytokine production. Cells were stained with carboxyfluorescein succinimidyl ester (SigmaAldrich, St. Louis, MO; $5 \mu \mathrm{M}$ ) for $5 \mathrm{~min}$ at room temperature. Labeled splenocytes were stimulated with media containing recombinant MOMP $\left(10 \mu \mathrm{g}\right.$ per well) for $96 \mathrm{~h}$ at $37^{\circ} \mathrm{C}$ with $5 \% \mathrm{CO}_{2}$. Cells were incubated for an additional $12 \mathrm{~h}$ in complete Dulbecco's minimal essential medium containing brefeldin A (Sigma-Aldrich; $10 \mu \mathrm{g} \mathrm{ml}^{-1}$ ) before intracellular cytokine staining.

MOMP-specific antibody quantification, in vitro neutralization of Chlamydia infectivity and opsonization. Antigen-specific antibodies were measured by enzyme-linked immunosorbent assay and in vitro $C$. muridarum neutralization assay were performed as previously described. $^{21}$

Monocytes/macrophage cell line RAW264.7 (ATCC TIB-71) were grown in RPMI 1640, HEPES, $10 \%$ v/fetal calf serum, $4 \mathrm{~mm}$ L-glutamine, $50 \mu \mathrm{g} \mathrm{ml}^{-1}$ gentamicin, $100 \mu \mathrm{g} \mathrm{ml}^{-1}$ streptomycin. C. muridarum was incubated with a $1 / 20$ dilution of serum for $1 \mathrm{~h}$ at $37^{\circ} \mathrm{C}$ with $5 \% \mathrm{CO}_{2}$, then added to RAW264.7 cells at an MOI of 1 and incubated for 2, 4, 6, and $24 \mathrm{~h}$.

Intrapenile and intravaginal infections. Intrapenile challenges were performed on mice by exposing the glans and inoculating the exterior of the urethra with $1 \times 10^{6}$ IFU of $C$. muridarum in $5 \mu \mathrm{l}$ of sucrosephosphate-glutamine (SPG; $219 \mathrm{~mm}$ sucrose, $3.8 \mathrm{~mm} \mathrm{KH}_{2} \mathrm{PO}_{4}, 8.6 \mathrm{~mm}$ $\mathrm{Na}_{2} \mathrm{HPO}_{4}, 4.9 \mathrm{~mm}$ glutamic acid, $\mathrm{pH} 7.35$ ).

Female mice received $2.5 \mathrm{mg}$ of medroxyprogesterone (DepoProvera Pfizer, New York City, NY) subcutaneously, seven days before challenge with C. muridarum. Mice anaesthetized with ketamine (Parnell Laboratory, Sydney, Australia; $100 \mathrm{mg} \mathrm{kg}^{-1}$ )/xylazine (Bayer, Leverkusen, Germany; $10 \mathrm{mg} \mathrm{kg}^{-1}$ ) were challenged intravaginally with $C$. muridarum in $20 \mu \mathrm{l}$ of SPG two weeks following immunization. Mice recovering from a primary infection of $5 \times 10^{1}, 1 \times 10^{2}$, or $5 \times 10^{2}$ IFU ( 6 weeks) were also rechallenged with the same dose as the primary infection to act as a LIC group.

Prostatic fluid collection, mating, and sexual transmission. Male mice were maintained under isoflurane-induced anesthesia and placed on their backs for collecting prostatic fluid. Urine was drained from the bladder using a syringe before collection. Ejaculation was induced following electro-stimulation of the prostate using a custom made probe and the square wave generator (Universal KymographHarvard Bioscience Inc., Holliston, MA) (Supplementary Figure 6). The prostatic fluid was collected into a capillary tube and expelled into a tube before making the volume up to $20 \mu \mathrm{l}$ with cold SPG.

Infected males were mated with non-progesterone primed females during the peak of their infection (days 7-14 p.i.) at the beginning of the $12 \mathrm{~h}$ dark cycle. Paired mice were observed for $1 \mathrm{~h}$ and vaginal lavages were collected following the first instances in which a female mated with a male for $\geq 10 \mathrm{~s}$. Paired mice were then left for the remaining dark cycle and inspected for vaginal plugs at the beginning of the following $12 \mathrm{~h}$ light cycle. Vaginal plugs were excised and homogenized in $800 \mu \mathrm{l}$ of SPG using the OMNI TH tissue homogenizer (OMNI International, Kennesaw, GA). The uterine horns were flushed with $200 \mu \mathrm{l}$ of the same SPG containing the vaginal plug.

Quantification of $C$. muridarum from secretions, tissues, and swabs. Infected tissues ( $\leq 250 \mathrm{mg}$ ) were excised and homogenized in $800 \mu \mathrm{l}$ of SPG. Vaginal swabs were collected using a sterile nasopharyngeal swab (Copan, Murrieta, CA) and stored in $500 \mu$ of SPG containing two glass beads. The SPG supernatant was used to quantify chlamydial content by culture as previously described. ${ }^{21}$ Ejaculate was also screened by culture and ompA-specific quantitative reverse transcription PCR as described previously. ${ }^{31}$ 
RNA extraction and reverse transcription PCR. Genital tract tissues were equilibrated in RNAlater (QIAGEN, Venlo, Netherlands) then total RNA was extract using the RNeasy Tissue Mini Kit (QIAGEN) (Cat. No. 74704) and treated with RNase-free DNase (QIAGEN). RNA was extracted immediately from sorted cells using Trizol (Invitrogen) and $10 \mu \mathrm{g}$ of glycogen carrier protein (Cat No. AM9510, Applied Biosystems, Foster City, CA) according to manufacturer's instructions. Complementary DNA was synthesized using High Capacity Reverse Transcriptase Kit (Applied Biosystems) (Cat. No. 4368814) as per the manufacturer's instructions. Each reaction contained $10 \mathrm{ng}$ of complementary DNA, $1 \mu \mathrm{M}$ of forward/reverse primers (Supplementary Figure 7) (SigmaAldrich), $200 \mu \mathrm{M}$ dNTP's, $1.5 \mathrm{mM} \mathrm{MgCl}_{2}, 1 \mathrm{X}$ buffer, 0.15X SYBR green, and $5 \mathrm{U}$ of Platinum Taq polymerase (Invitrogen) made up to a final $20 \mu \mathrm{L}$ volume using sterile endonuclease-free water. Reverse transcription PCR was performed using the Corbet Rotorgene Q (QIAGEN). Gene expression was analyzed using the Hierarchical Clustering Explorer 3.5 Analysis Tool (University of Maryland, College Park, MD).

Immunohistochemistry. Immunohistochemistry was performed by the HistoTechnology Facility (Queensland Institute of Medical Research, Brisbane, QLD, Australia) as described previously. ${ }^{21}$

Gross oviduct pathology. The oviduct diameter was measured on day 35 p.i. to assess the severity of pathology. ${ }^{33,34}$ The incidence of oviduct pathology (presence or absence) was the number of mice presenting with hydrosalpinx (unilateral and bilateral).

Power calculations and statistical analysis. Sample sizes were determined a priori using a one-tailed, Proportions: Inequality, two independent groups Fischer's exact test in $\mathrm{G}^{\star}$ Power 3.1.7 software (Institute for Experimental Psychology, Dusseldorf, Germany). Statistical analysis of graphical data was performed using GraphPad Prism version 5.00 (GraphPad, La Jolla, CA).

Ethics statement. Animal care and use protocols in this study adhered to the National Health and Medical Research Council guidelines to promote the well-being of animals used for scientific purposes. This study was approved by the Queensland University of Technology Animal Ethics Committee (QUT UAEC No. 1100000588 and 1400000010) and carried out in strict accordance with any recommendations. All animals were euthanized humanely by intraperitoneal injection with sodium pentobarbital $\left(200 \mathrm{mg} \mathrm{kg}^{-1}\right)$.

SUPPLEMENTARY MATERIAL is linked to the online version of the paper at http://www.nature.com/mi

\section{ACKNOWLEDGMENTS}

This work was supported by the Queensland Government Smart State National and International Research Alliances Program, Australia-CanadaIndia Chlamydia Research Alliance, National Health and Medical Research Council $(553055,1062198$ and 1049571) and the Michael Smith Foundation Post-Doctoral Fellowship, and we thank Peter Timms for his contribution towards acquiring this funding. We thank Donna West and Jo-Anne Finnimore from QUT for their assistance with animal monitoring/housing and cytospin/Geimsa staining, respectively. We thank Genentech Inc. for the purified $\alpha \mathrm{CD} 20$ antibody. We would also like to thank Clay Winterford and Nigel Waterhouse at the HistoTechnology Facility-Queensland Institute of Medical Research (QIMR) Berghofer Medical Research Institute for performing the immunohistochemistry and slide scanning.

\section{DISCLOSURE}

The authors declare no conflict of interest.

(c) 2016 Society for Mucosal Immunology

\section{REFERENCES}

1. ABS. Year book Australia 2012 2012, Available athttp://www.abs.gov. au/ausstats/abs@.nsf/Lookup/bySubject/1301.0 2012 Main Features C Communicable diseases $\sim 232$.
2. Gerbase, A.C., Rowley, J.T., Heymann, D.H., Berkley, S.F. \& Piot, P. Global prevalence and incidence estimates of selected curable STDs. Sex. Transm. Infect. 74 (Suppl 1), S12-S16 (1998).

3. Stamm, W.E. \& Holmes, K.K. Chlamydia trachomatis infections of the adult, 2nd ed. Holmes, K.K. \& Sparling, P.F. \& Stamm, W.E. \& Piot, P. \& Wasserheit, J.N. \& Corey, L., (eds.) McGraw-Hill, New York, NY (1990).

4. Patel, R. et al. International Handbook of Chlamydia, 3rd (edn) Moss, T.R., (eds). Alden Press, Haslemere, 2008, 205 p.

5. Gray, R.T., Beagley, K.W., Timms, P. \& Wilson, D.P. Modeling the impact of potential vaccines on epidemics of sexually transmitted Chlamydia trachomatis Infection. J. Infect. Dis. 199, 1680-1688 (2009).

6. Tuffrey, M. \& Taylor-Robinson, D. Progesterone as a key factor in the development of a mouse model for genital-tract infection with Chlamydia trachomatis. FEMS Microbiol. Lett. 12, 111-115 (1981).

7. Coleman, D.L. et al. Biology of the Laboratory Mouse, 2nd (ed). Green, E.L., (ed) Dover Publications, Inc, New York, NY, (1968), 706 p.

8. Carey, A.J., Cunningham, K.A., Hafner, L.M., Timms, P. \& Beagley, K.W. Effects of inoculating dose on the kinetics of Chlamydia muridarum genital infection in female mice. Immunol. Cell Biol. 87, 337-343 (2009).

9. Maxion, H.K., Liu, W., Chang, M.H. \& Kelly, K.A. The infecting dose of Chlamydia muridarum modulates the innate immune response and ascending infection. Infect. Immun. 72, 6330-6340 (2004).

10. Al-Mously, N., Cross, N.A., Eley, A. \& Pacey, A.A. Real-time polymerase chain reaction shows that density centrifugation does not always remove Chlamydia trachomatis from human semen. Fertil. Steril. 92, 1606-1615 (2009).

11. Mount, D.T., Bigazzi, P.E. \& Barron, A.L. Experimental genital infection of male guinea pigs with the agent of guinea pig inclusion conjunctivitis and transmission to females. Infect. Immun. 8, 925-930 (1973).

12. Rank, R.G., Bowlin, A.K., Reed, R.L. \& Darville, T. Characterization of chlamydial genital infection resulting from sexual transmission from male to female guinea pigs and determination of infectious dose. Infect. Immun. 71, 6148-6154 (2003).

13. Robertson, S.A., Guerin, L.R., Bromfield, J.J., Branson, K.M., Ahlstrom, A.C. \& Care, A.S. Seminal fluid drives expansion of the CD4 + CD25 + T regulatory cell pool and induces tolerance to paternal alloantigens in mice. Biol. Reprod. 80, 1036-1045 (2009).

14. Farris, C.M. \& Morrison, R.P. Vaccination against Chlamydia genital infection utilizing the murine C. muridarum model. Infect. Immun. 79, 986-996 (2011).

15. Morelli, A.B., Becher, D., Koernig, S., Silva, A., Drane, D. \& Maraskovsky, E. ISCOMATRIX: a novel adjuvant for use in prophylactic and therapeutic vaccines against infectious diseases. J. Med. Microbiol. 61, 935-943 (2012).

16. O'Meara, C.P., Andrew, D.W. \& Beagley, K.W. The mouse model of Chlamydia genital tract infection: a review of infection, disease, immunity and vaccine development. Curr. Mol. Med. 14, 396-421 (2013).

17. Farris, C.M., Morrison, S.G. \& Morrison, R.P. CD4 + T cells and antibody are required for optimal major outer membrane protein vaccine-induced immunity to Chlamydia muridarum genital infection. Infect. Immun. 78, 4374-4383 (2010).

18. Gebhardt, T., Wakim, L.M., Eidsmo, L., Reading, P.C., Heath, W.R. \& Carbone, F.R. Memory Tcells in nonlymphoid tissue that provide enhanced local immunity during infection with herpes simplex virus. Nat. Immunol. 10, 524-530 (2009).

19. Olsen, A.W., Follmann, F., Erneholm, K., Rosenkrands, I. \& Andersen, P. Protection against Chlamydia trachomatis infection and upper genital tract pathological changes by vaccine-promoted neutralizing antibodies directed to the vd4 of the major outer membrane protein. J. Infect. Dis. 212, 978-989 (2015).

20. Kobzik, L., Huang, S., Paulauskis, J.D. \& Godleski, J.J. Particle opsonization and lung macrophage cytokine response. In vitro and in vivo analysis. J. Immunol. 151, 2753-2759 (1993).

21. O'Meara, C.P. et al. Immunity against a Chlamydia infection and disease may be determined by a balance of IL-17 signaling. Immunol. Cell Biol. 92, 287-297 (2013).

22. Mueller, S.N., Gebhardt, T., Carbone, F.R. \& Heath, W.R. Memory T cell subsets, migration patterns, and tissue residence. Annu. Rev. Immunol. 31, 137-161 (2012). 
23. Schenkel, J.M., Fraser, K.A., Vezys, V. \& Masopust, D. Sensing and alarm function of resident memory CD8(+) T cells. Nat. Immunol. 14, 509-513 (2013).

24. Laidlaw, B.J. et al. CD4 + T cell help guides formation of CD103 + lungresident memory CD8 + T cells during influenza viral infection. Immunity 41, 633-645 (2014).

25. Shin, H. \& Iwasaki, A. A vaccine strategy that protects against genital herpes by establishing local memory T cells. Nature 491, 463-467 (2012).

26. Craig, A.P. et al. A 5-year Chlamydia vaccination programme could reverse disease-related koala population decline: Predictions from a mathematical model using field data. Vaccine 32, 4163-4170 (2014).

27. Fijak, M. \& Meinhardt, A. The testis in immune privilege. Immunol. Rev. 213, 66-81 (2006).

28. Armitage, C.W., O'Meara, C.P., Harvie, M.C., Timms, P., Blumberg, R.S. \& Beagley, K.W. Divergent outcomes following transcytosis of lgG targeting intracellular and extracellular chlamydial antigens. Immunol. Cell Biol. 92, 417-426 (2013).

29. Mayhew, A. et al. Risk perceptions and subsequent sexual behaviors after HPV vaccination in adolescents. Pediatrics 133, 404-411 (2014).
30. Caldwell, H.D., Kromhout, J. \& Schachter, J. Purification and partial characterization of the major outer membrane protein of Chlamydia trachomatis. Infect. Immun. 31, 1161-1176 (1981).

31. O'Meara, C.P., Armitage, C.W., Harvie, M.C.G., Timms, P., Lycke, N.Y. \& Beagley, K.W. Immunization with a MOMP-based vaccine protects mice against a pulmonary Chlamydia challenge and identifies a disconnection between infection and pathology. PLOS One 8, e61962 (2013).

32. Smyth, M.J., Thia, K.Y., Street, S.E., MacGregor, D., Godfrey, D.I. \& Trapani, J.A. Perforin-mediated cytotoxicity is critical for surveillance of spontaneous lymphoma. J. Exp. Med. 192, 755-760 (2000).

33. Shah, A.A. et al. Histopathologic changes related to fibrotic oviduct occlusion after genital tract infection of mice with Chlamydia muridarum. Sex. Transm. Dis. 32, 49-56 (2005).

34. Imtiaz, M.T., Schripsema, J.H., Sigar, I.M., Kasimos, J.N. \& Ramsey, K.H. Inhibition of matrix metalloproteinases protects mice from ascending infection and chronic disease manifestations resulting from urogenital Chlamydia muridarum infection. Infect. Immun. 74, 5513-5521 (2006). 